\title{
Flavonoid Rich Fraction of Holarrhena antidysenterica Leaves Attenuate Hyperglycemia by Ameliorating Hyperlipidemia and Oxidative Stress in Type II Diabetes in Rats
}

\author{
Deepti Bandawane*1, Manasi Patil ${ }^{1}$ and Shailaja Jadhav ${ }^{2}$ \\ ${ }^{1}$ Department of Pharmacology, India \\ ${ }^{2}$ Department of Pharmaceutical Chemistry, India \\ *Corresponding author: Deepti Banadawane, Department of Pharmacology, Maharashtra, India
}

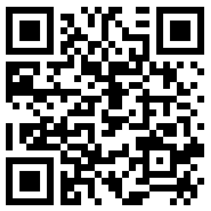

\section{ARTICLE INFO}

Received: 慧 March 12, 2019

Published: March 21, 2019

Citation: Deepti Bandawane, Manasi Patil, Shailaja Jadhav. Flavonoid Rich Fraction of Holarrhena antidysenterica Leaves Attenuate Hyperglycemia by Ameliorating Hyperlipidemia and Oxidative Stress in Type II Diabetes in Rats. Biomed J Sci \& Tech Res 16(2)2019. BJSTR. MS.ID.002821.

Keywords: Antihyperglycemic; Streptozotocin; Holarrhena Antidysenterica; Antihyperlipidemic; Antioxidant

Abbreviations: IDF: International Diabetes Federation; FCR: Folin Ciocalteu's Reagent; SGOT: Serum Glutamate Oxaloacetate Transaminase; SGPT: Serum Glutamate Pyruvate Transaminase; ALP: Alkaline Phosphates; OGTT: Oral Glucose Tolerance Test; AST: Aspartate Transaminase; ALT: Alanine Transaminase; ALP: Alkaline Phosphatase

\section{ABSTRACT}

Objective: Holarrhena antidysenterica (Apocynaceae) is an indigenous plant used traditionally for the treatment of diabetes and associated complications. However the antihyperglycemic potential of the plant is not scientifically evaluated. Objective of the present study was to investigate the antihyperglycemic activity of ethyl acetate fraction of Holarrhena antidysenterica leaves (EAHA) in streptozotocin- nicotinamide induced type II diabetes in rats, and to focus on its possible mechanism of action.

Methods: Diabetes was induced by intraperitoneal injection of nicotinamide (120 $\mathrm{mg} / \mathrm{kg}) 15 \mathrm{~min}$ before STZ (60 mg/kg, i.p.). Animals were divided in six groups $(\mathrm{n}=6)$ and treated with $100 \mathrm{mg} / \mathrm{kg}, 200 \mathrm{mg} / \mathrm{kg}$ and $400 \mathrm{mg} / \mathrm{kg}$ of EAHA. At the end of study period, fasting blood glucose, oral glucose tolerance, serum insulin, glycosylated haemoglobin, total proteins, serum albumin, glycogen in liver and skeletal muscles were determined. Antioxidant enzymes of kidney viz superoxide dismutase, catalase, reduced glutathione and MDA were evaluated in liver and kidney. Pancreas was subjected to histopathology study.

Results: Significant decrease in fasting blood glucose, oral glucose tolerance, lipid profile, total proteins and serum albumin was observed. Significant improvement in glycosylated $\mathrm{Hb}$, oxidative stress parameters of kidney and liver including superoxide dismutase, catalase and reduced glutathione has been observed in EAHA treated diabetic rats. Histopathology of kidney and pancreatic tissues showed structural improvement.

Conclusion: Present study has revealed the antihyperglycemic potential of EAHA by improving the disturbed glucose homeostasis along with hyperlipidemia and by amelioration of oxidative stress.

\section{Introduction}

Diabetes mellitus is a metabolic disorder of the endocrine system with pathological disturbances, resulting in various micro and macro vascular complications. It is characterized by high blood glucose levels due to the inability of the body's cells to utilize glucose properly [1,2]. Globally, the estimated incidence of diabetes and projection for year 2030, as given by International Diabetes
Federation (IDF) is 350 million [3]. This worldwide epidemic of diabetes has been stimulating the search for new concepts and targets for the treatment of this incurable but controllable disease. The currently available antidiabetic agents including sulphonylureas, biguanides, thiazolidinediones, $\alpha$ - glucosidase inhibitors and GLP-1 antagonist are widely used to control the hyperglycemia but fail to 
significantly alter the course of diabetic complications. Moreover they have limited use because of undesirable side effects, high rates of secondary failure and in addition they are not suitable for use during pregnancy [4]. Alternative strategies to the current modern pharmacological therapy of diabetes mellitus are urgently needed because of the inability of existing modern therapies to control all the pathological aspects of the disorder, as well as the enormous cost and poor availability of the modern therapies for many rural populations in developing countries. Plants used in traditional medicine to treat diabetes mellitus represent a valuable alternative for the control of this disease. Several plant species have proven to have hypoglycemic effect [5-7].

Despite of the presence of several antidiabetic agents in the market due to their disadvantages, the search for more effective and safer agents has continued to be an important area of research. Herbal remedies are apparently effective, produce minimal or no side effects in clinical experience and are of relatively low costs as compared to oral synthetic hypoglycemic agents. There are many medicinal plants known to be used in the treatment of diabetes and a number of plants have been screened positive for their antidiabetic effect. Most of these plants were found to belong to the chemical group including glycosides, alkaloids and flavonoids [8,9]. Holarrhena antidysenterica Linn belonging to family Apocynaceae commonly known as kurchi or kutja is a typical Indian medicinal plant. It is distributed throughout the world and is rich of flavonoids and alkaloids. The bark and seeds are used to treat amoebic dysentery, diarrhea, asthma, bronchopneumonia and malaria $[10,11]$. The survey of literature reveals that various parts such as roots, bark, leaves, flowers, fruits and seeds of Holarrhena antidysenterica (Linn) Wall has been traditionally documented to possess antidiabetic activity. There are few studies of different parts of this plant related to its hypoglycemic effect. Ethanolic extract of fruit has shown hypoglycemic activity in rats \& also known to contain various polyphenolic compounds like flavonoids, tannins, etc related to antidiabetic potential $[12,13,5]$. But there is no published scientific data for antidiabetic activity of leaves of Holarrhena antidysenterica; hence the present study aims to investigate the ability of ethyl acetate fraction of Holarrhena antidysenterica Linn leaves (EAHA) to cure disturbed glucose homeostasis in STZ- nicotinamide induced diabetes associated with insulin resistance.

\section{Materials and Methods}

\section{Plant material}

The leaves of Holarrhena antidysentrica Linn were collected from the National research institute of basic ayurvedic sciences, Pune in the month of August 2013. The plant was identified and authenticated by National research institute of basic ayurvedic sciences, Pune and a voucher specimen (V.No-4405) was deposited in the herbarium for future reference. The leaves were dried in shade and ground to a coarse powder by using a dry grinder.

\section{Animals}

Wistar rats of either sex (180 - 200g) were procured from National Institute of Bioscience, Pune. Animal were housed in standard polypropylene cages lined with raw husk. The animal house was maintained on $12 \mathrm{~h}$ light/dark cycle at approximately $22 \pm 2^{\circ} \mathrm{C}$, relative humidity $60-70 \%$. The animals were provided with standard laboratory diet procured from Nutrivet life sciences, Pune and water ad libitum. The animals were randomly assigned to different experimental groups and a minimum period of 7 days was allowed for adaptation before start of the experiment. The animals described as fasting were deprived of food for $24 \mathrm{~h}$ before experimentation but allowed free access to water throughout. The study protocol was approved by Institutional Animal Ethical Committee (IAEC) of the Institute in accordance with the regulations of CPCSEA (884/ac/05/CPCSEA).

\section{Preparation of Ethyl Acetate Fraction}

The crude hydroalcoholic extract was prepared by cold maceration technique using methanol: water (70:30) as solvent system. This crude extract was partitioned into soluble and insoluble fraction using $500 \mathrm{ml}$ of ethyl acetate solvent. The solvent was filtered using absorbent cotton wool and filter paper. Filtrates were collected and evaporated on rota evaporator at $40{ }^{\circ} \mathrm{C}$ to obtain a yield of $11.16 \% \mathrm{w} / \mathrm{w}$. The obtained ethyl acetate fraction (EAHA) was preserved in refrigerator till further use [14].

\section{Chemicals and Drugs}

Streptozotocin (STZ) was purchased from Sigma-Aldrich (St. Louis, MO, USA). Nicotinamide was purchased from Sisco Lab and Sitagliptine was procured from MSD Pharmaceuticals, Puducherry. All other chemicals were procured from local sources and were of analytical grade.

\section{Determination of Total Phenolic Content}

The total phenolic content of EAHA was determined with the Folin- Ciocalteu's reagent (FCR) method described by Shwetha et al. [15]. In the procedure, different concentrations of the extracts were mixed with $0.4 \mathrm{ml} \mathrm{FCR} \mathrm{(diluted} \mathrm{1:10} \mathrm{v/v).} \mathrm{After} 5 \mathrm{~min} 4 \mathrm{ml}$ of sodium carbonate solution was added. The final volume of the tubes were made upto $10 \mathrm{ml}$ with distilled water and allowed to stand for $90 \mathrm{~min}$ at room temperature. Absorbance of sample was measured against the blank at $750 \mathrm{~nm}$ using a spectrophotometer (Shimadzu UV-1609, Japan). A calibration curve was constructed using catechol solutions as standard and total phenolic content of the extract was expressed in terms of milligrams of catechol per gram of dry weight.

\section{Determination of Total Tannin Content}

Total tannin content was determined by hide powder test according to the WHO procedure in which weight difference between tanned and untanned hide powder was used for quantitative determination of tannins [16]. 


\section{Determination of Total Flavonoid Content}

The total flavonoid content was measured by means of an aluminium chloride assay [17] with slight modification. $1 \mathrm{ml}$ of EAHA or standard solutions of quercetin $(10-50 \mathrm{mg} / \mathrm{ml})$ was added to $4 \mathrm{ml}$ of $50 \%$ solution of methanol with $0.3 \mathrm{ml}$ of $5 \%$ NaNO2. $0.3 \mathrm{ml}$ of $10 \% \mathrm{AlCl} 3$ was added after $5 \mathrm{~min}$ and at the 6 th min, $2 \mathrm{ml} \mathrm{NaOH} \mathrm{(1M)} \mathrm{solution} \mathrm{was} \mathrm{added,} \mathrm{the} \mathrm{total} \mathrm{volume} \mathrm{was}$ made up to $10 \mathrm{ml}$ with distilled water. The solution was mixed well and the absorbance was measured against the reagent blank at $510 \mathrm{~nm}$. The total flavonoid content $(\mathrm{mg} / \mathrm{g}$ ) was determined from the calibration curve and expressed as mg quercetin equivalents. All the determinations were carried out in triplicate, and the mean values were calculated.

\section{High Performance Thin Layer Chromatography (Hptlc)}

HPTLC chromatography was performed using toluene: ethyl acetate: formic acid $(5: 4: 1, \mathrm{v} / \mathrm{v} / \mathrm{v})$ as mobile phase and the standard biomarkers used were quercetin and gallic acid. The development was carried out using $20 \mathrm{ml}$ of mobile phase in a glass chamber (Camag) previously saturated with mobile phase for $15 \mathrm{~min}$ at room temperature $(25 \pm 20 \mathrm{C})$ and relative humidity $60 \% \pm 5 \%$. HPTLC analysis was performed at $270 \mathrm{~nm}$ in reflectance mode with a Camag TLC scanner III operated by WinCATS software [18].

\section{In Vitro $\alpha$-Amylase and $\alpha$-Glucosidase Inhibition Assay}

$\alpha$-amylase and $\alpha$-glucosidase inhibition assay was carried out according to the method described by Ranilla [19]. The percentage inhibition was calculated using the following formula:

$$
\text { Inhibition }(\%)=\frac{\text { Absorbance of standard }- \text { Absorbance of test }}{\text { Absorbance of standard }} \times 100
$$

\section{Acute Toxicity Studies}

Acute oral toxicity study was performed as per OECD guidelines 423 using wistar rats. The animals were fasted overnight with free access to water. EAHA was administered orally to different groups at increasing dose levels of 50,100, 300, 2000 and 5000mg/kg body weight. Thereafter the animals were observed for $2 \mathrm{~h}$ and then intermittently for further $4 \mathrm{~h}$ for any kind of changes in behavioural, neurological and autonomic profiles. Animals are observed for mortality if any from $24 \mathrm{~h}$ to 14 days [20].

\section{Experimental Design}

Experimental Induction of Diabetes Mellitus : Diabetes was induced by intraperitoneal injection of nicotinamide $(120 \mathrm{mg} /$ $\mathrm{kg}) 15 \mathrm{~min}$ before STZ (60mg/kg, i.p.) dissolved freshly in $0.05 \mathrm{M}$ citrate buffer (PH 4.5). Induction of diabetes was checked by the elevated blood glucose levels determined at $72 \mathrm{~h}$, and then on day 7 after injection. The rats with fasting blood glucose level higher than $200 \mathrm{mg} / \mathrm{dl}$ were selected for the study [21,22].

Experimental Groups: After the successful induction of experimental diabetes, the rats were divided into six groups each comprising six rats. a. Group 1: Normal control rats administered CMC suspension $(0.1 \%)$

b. Group 2: Diabetic control rats i.e. rats treated with streptozotocin $(65 \mathrm{mg} / \mathrm{kg})$ and nicotinamide $(120 \mathrm{mg} / \mathrm{kg}$ i.p)

c. Group 3: Diabetic rats treated with $100 \mathrm{mg} / \mathrm{kg}$ of EAHA.

d. Group 4: Diabetic rats treated with $200 \mathrm{mg} / \mathrm{kg}$ of EAHA.

e. Group 5: Diabetic rats treated with $400 \mathrm{mg} / \mathrm{kg}$ of EAHA.

f. Group 6: Diabetic rats treated with $3 \mathrm{mg} / \mathrm{kg}$ sitagliptin (standard oral hypoglycemic drug)

EAHA as well as sitagliptin were suspended in CMC (0.1\%) and administered via oral route using oral feeding needle once daily for $28 \mathrm{~d}$.

\section{Evaluation of Antidiabetic activity}

Fasting Blood Glucose and Oral Glucose Tolerance Test: Fasting blood glucose was determined on 0 , 7th, 14th, 21st, and 28th day of the study period using a glucometer (Accu Check, Blutzuckermessgeraten, Germany). Oral glucose tolerance test was performed in overnight fasted $(18 \mathrm{~h})$ diabetic rats at the end of 28th day of study. Glucose $(3 \mathrm{~g} / \mathrm{kg}$ ) was fed $30 \mathrm{~min}$ after the administration of extracts or standard drug. Blood glucose was determined at $0,30,60,90$ and 120 min of glucose administration [23].

Glycosylated Hemoglobin and Plasma Insulin: Glycosylated hemoglobin (HbA1c \%) was determined in EDTA-blood samples obtained at the end of the 28th day study using commercial assay kit (Crest biosystems, Goa, India). Blood samples were centrifuged at $7000 \mathrm{rpm}$ for $15 \mathrm{~min}$ at $4^{\circ} \mathrm{C}$ to separate the serum. Insulin concentrations were determined through a radio immunoassay procedure, using insulin kit (Coral, India) according to manufacturer's instructions.

\section{Evaluation of Antihyperlipidemic Activity}

At the end of 28 days, blood was collected from inferior vena cava, serum separated for determination of parameters like total cholesterol, HDL- cholesterol and triglycerides using commercially available kits (Span diagnostics). VLDL cholesterol and LDLcholesterol were calculated using the Friedewald's formula

\section{[24].Evaluation of Antioxidant Activity}

Estimation of Reduced Glutathione (GSH) In Liver and Kidney: Reduced glutathione was estimated according to method described by Kaur et al [25]. 1.0ml of sulfosalicylic acid (4.0\%) was used to precipitate the tissue homogenate $(1.0 \mathrm{ml}) .0 .5 \mathrm{ml}$ of filtered aliquot was added to $2.3 \mathrm{ml}$ of sodium phosphate buffer (0.1M, pH 7.4) and $0.2 \mathrm{ml}$ dithiobisnitrobenzoate (DTNB) to make a total volume of $3.0 \mathrm{ml}$. The optical density of yellow colour thus developed was read immediately at $412 \mathrm{~nm}$. The unknown GSH concentration was estimated by extrapolation from the standard curve and expressed as $\mathrm{U} / \mathrm{mg}$ protein. 
Estimation of Superoxide Dismutase (SOD) In Liver and Kidney: SOD activity was measured according to method of Marklund [26]. Assay mixture includes $2.95 \mathrm{ml}$ Tris- $\mathrm{HCl}$ buffer, $25 \mu \mathrm{l}$ of pyrogallol and $0.05 \mathrm{ml}$ of tissue homogenate in total volume of 3 $\mathrm{ml}$. The difference between the optical densities obtained at 1.30 and 3.30 minutes was estimated and expressed as $\mathrm{U} / \mathrm{mg}$ protein.

Estimation of Catalase (CAT) In Liver and Kidney: Catalase was measured according to method described by Sahreen et al [27]. Sample readings were taken by addition of $1 \mathrm{ml}$ of phosphate buffer and $5 \mu$ of tissue homogenate in the reference cuvette and test cuvette. Hydrogen peroxide $(10 \mu \mathrm{l})$ was then added in the test cuvette in the spectrophotometer. Reading was taken at $240 \mathrm{~nm}$, 1 min after placing the cuvettes in the spectrophotometer and expressed as $\mathrm{U} / \mathrm{mg}$ protein.

Estimation of Liver and Renal MDA Lipid Peroxidation: MDA lipid peroxidation was estimated according method described by Kumar et al [28]. Briefly, the homogenate was incubated with $15 \% \mathrm{TCA}, 0.38 \% \mathrm{TBA}$ and $5 \mathrm{~N} \mathrm{HCl}$ at $95^{\circ} \mathrm{C}$ for $15 \mathrm{~min}$. The mixture was cooled, centrifuged and the absorbance of the supernatant was measured at $532 \mathrm{~nm}$ against appropriate blank and expressed as $\mathrm{nmol} / \mathrm{mg}$ protein.

\section{Liver Glycogen Estimation}

Liver of individual animal was homogenized in 5\% w/v trichloroacetic acid and its glycogen content was estimated by the method of Carrol et.al [29].

\section{Evaluation of Liver Function Parameters}

Serum glutamate oxaloacetate transaminase (SGOT), serum glutamate pyruvate transaminase (SGPT) and alkaline phosphates (ALP) were analysed by using commercial kits (Crest Biosystems, Goa, India).

\section{Histopathological Studies}

At the end of study duration all the animals were sacrificed, and the pancreas, liver, heart and kidney were isolated for histopathological estimation [30].

\section{Statistical Analysis}

All the data are presented as Mean \pm SEM of measurements made on six animals in each group. Statistical analysis was performed with a one-way analysis of variance (ANOVA) followed by Dunnet's multiple test of comparison using Graph Pad Instat (version-3) software. A value of $\mathrm{p}<0.05$ was statistically significant compared with the respective control.

\section{Results}

\section{Percentage Yield}

The yield of hydroalcoholic extract of $\mathrm{H}$. antidysentrica leaves was found to be $28.9 \% \mathrm{w} / \mathrm{w}$ while that of EAHA was $11.66 \% \mathrm{w} / \mathrm{w}$.

\section{Quantitative Phytochemical Analysis}

The total phenolic content of EAHA was found to be $4.3 \mathrm{mg}$ of Catechol equivalents $100 \mathrm{mg}$ dried extract. The total tannin content of EAHA was found to be $20 \% \mathrm{w} / \mathrm{w}$ while the total flavonoid content of EAHA was found to be $108 \mathrm{mg}$ quercetin equivalent/g of fraction.

\section{High Performance Thin Layer Chromatography}

The overlay spectras of EAHA with gallic acid and EAHA with quercetin are shown in Figures 1 \& 2, respectively. Gallic acid and quercetin were resolved at Rf 0.60 and Rf 0.84 , respectively. The spectrum clearly reveals that EAHA contains more quercetin than gallic acid.

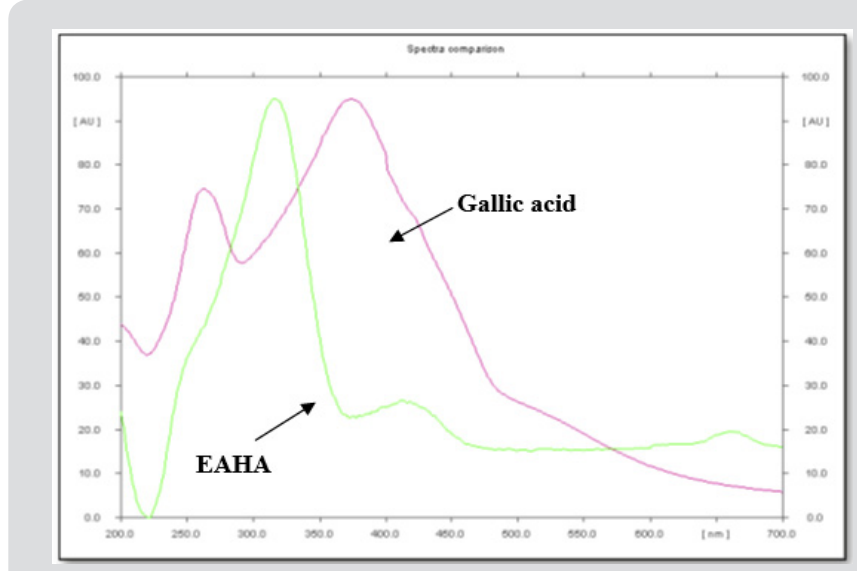

Figure 1: HPTLC chromatographic overlay spectra of EAHA with standard biomarker gallic acid at $270 \mathrm{~nm}$.

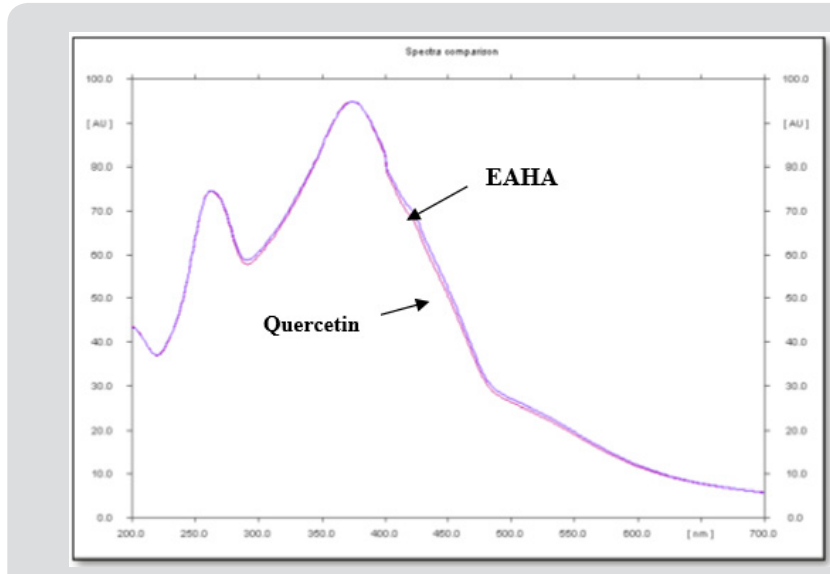

Figure 2: HPTLC chromatographic overlay spectra of EAHA with standard biomarker quercetin at $270 \mathrm{~nm}$.

\section{Acute Toxicity Study}

Results of the acute toxicity study revealed the non-toxic nature of EAHA. During the $14 \mathrm{~d}$ observation period, no behavioral, neurological or autonomic changes were observed. Further, there was no lethality or any toxic reaction in animals at a single large dose of $5000 \mathrm{mg} / \mathrm{kg}$. No mortality was recorded within the $14 \mathrm{~d}$ of observation. 


\section{Fasting Blood Glucose}

Treatment with EAHA for 4 weeks exhibited a significant $(p<0.01)$ decrease in the fasting blood glucose in STZ- NA induced diabetic rats as compared with the diabetic control (Figure 3). In diabetic rats, the blood glucose level was reduced by $56.88,64.05$, and $69.81 \%$ at 100,200 , and $400 \mathrm{mg} / \mathrm{kg}$ doses of EAHA, respectively. The standard oral hypoglycemic drug sitagliptin (3 mg/kg) showed $61.29 \%$ reduction in the blood glucose level as compared with the diabetic control group.

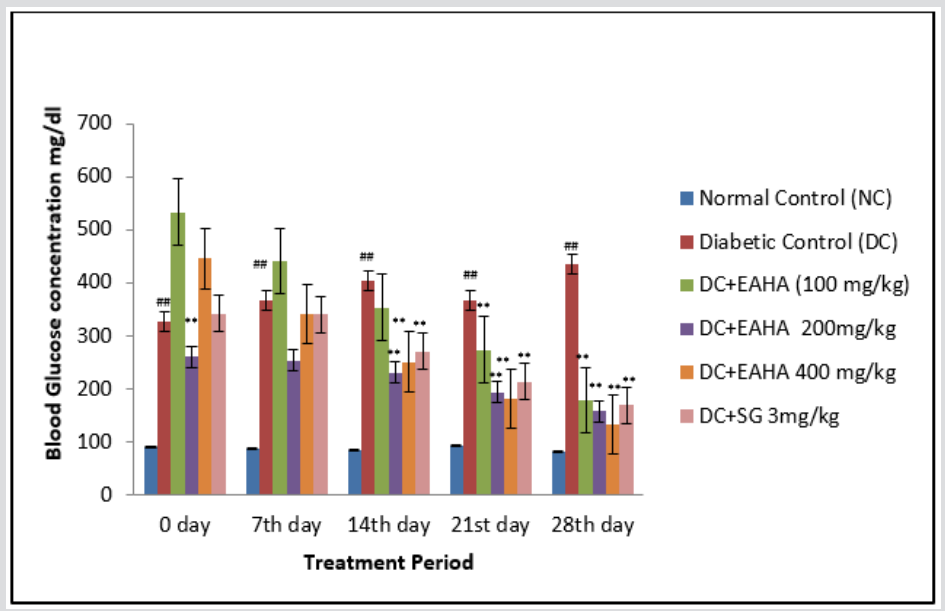

Figure 3: Effect of EAHA on fasting blood glucose in STZ-nicotinamide diabetic rats. NC: Normal control; DC: Diabetic control; EAHA: Ethyl acetate fraction of Holarrhena antidysenterica Linn. leaves; SG: Sitagliptine. Data are expressed as mean \pm S.E.M. $(n=6)$. \#\#: $p<0.01$ as compared to NC; **: $p<0.01$ as compared to DC. Data analysed by one way Analysis of Variance (ANOVA) followed by Dunnet's multiple test for comparison.

\section{Oral Glucose Tolerance Test (OGTT)}

As shown in Figure 4, the blood glucose of normal and diabetic rats increased significantly $(p<0.01)$ at $30 \mathrm{~min}$ after glucose administration. EAHA at all dose levels significantly $(p<0.01)$ reduced the increase in blood glucose at $90 \mathrm{~min}$ in glucose-loaded rats compared with diabetic control rats which showed elevation in the blood glucose throughout the total measurement period (120min).

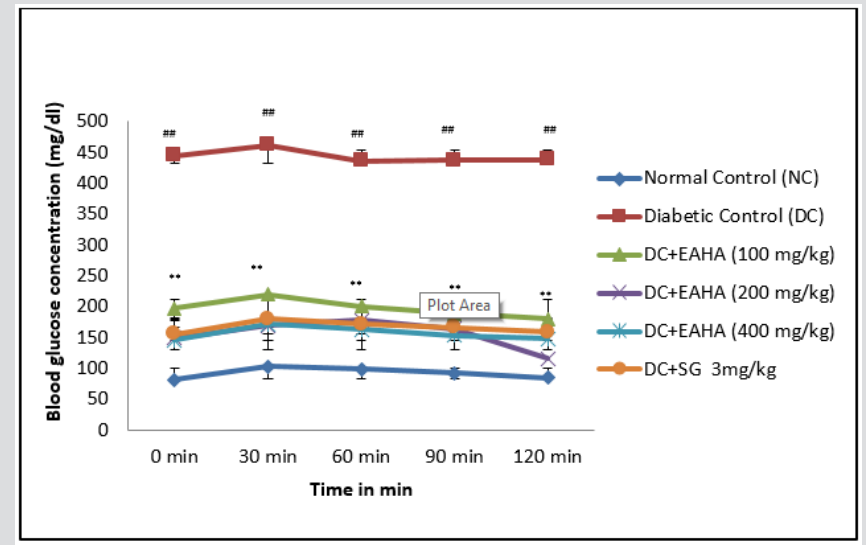

Figure 4: Effect of EAHA on OGTT in STZ-nicotinamide diabetic rats. NC: Normal control; DC: Diabetic control; EAHA: Ethyl acetate fraction of Holarrhena antidysenterica Linn. leaves; SG: Sitagliptine Data are expressed as mean \pm S.E.M. $(\mathrm{n}=6)$. \#\#: $\mathrm{p}<0.01$ as compared to NC; ${ }^{* *}: \mathrm{p}<0.01$ as compared to DC. Data analysed by one way Analysis of Variance (ANOVA) followed by Dunnet's multiple test for comparison.

\section{Lipid Profile}

The protective effect of EAHA on lipid profile has been shown in Figure 5. There was significant $(p<0.01)$ elevation in the levels of $\mathrm{T}-\mathrm{CH}$, triglycerides, LDL-CH and VLDL-CH and significant decrease $(\mathrm{p}<0.01)$ in serum HDL-CH when compared to normal rats. EAHA
$(200 \mathrm{mg} / \mathrm{kg})$ treated diabetic rats decreased T-CH by $39.12 \%$, TG by $47.58 \%$, LDL-CH by $66.34 \%$ and VLDL-CH by $45.99 \%$. Whereas EAHA $(200 \mathrm{mg} / \mathrm{kg})$ treated group showed a significant $(\mathrm{p}<0.01)$ increase in HDL-CH as compared to diabetic control group which is comparable with that of the standard drug sitagliptin. 


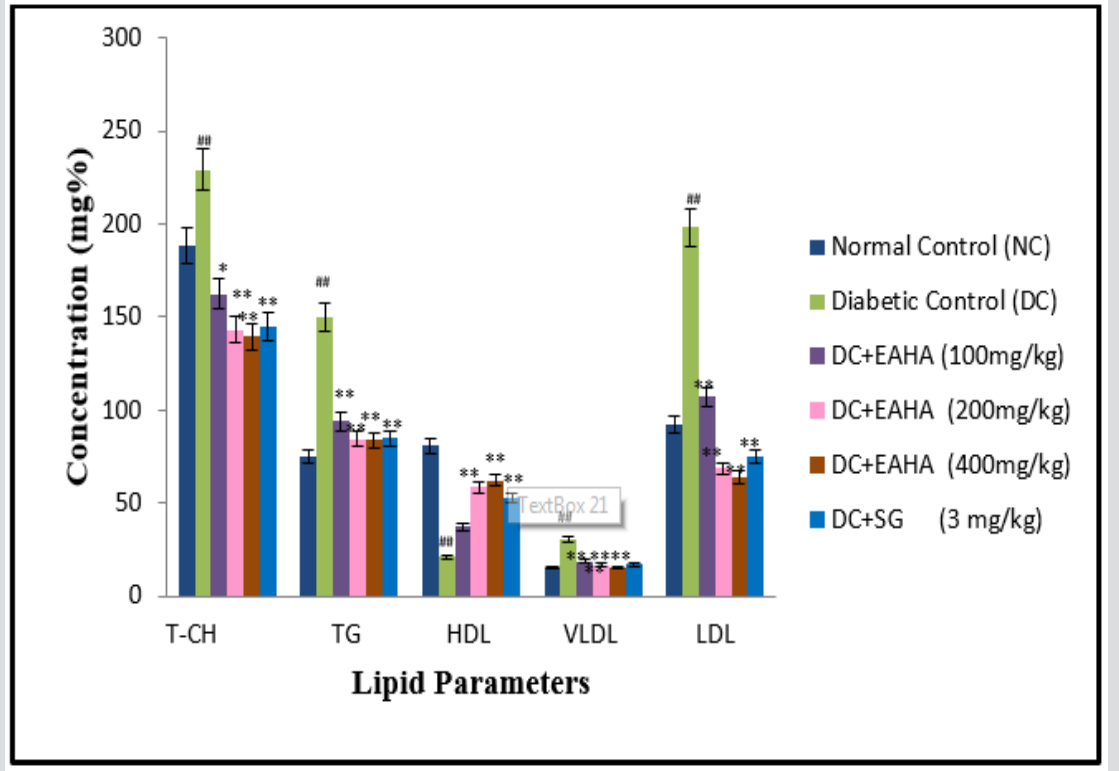

Figure 5: Effect of EAHA on lipid profile in STZ-nicotinamide diabetic rats. NC: Normal control; DC: Diabetic control; EAHA: Ethyl acetate fraction of Holarrhena antidysenterica Linn. leaves; SG: Sitagliptin; T-CH: Total Cholesterol; TG: Triglycerides; HDL: High density lipoprotein; LDL: Low density lipoprotein; VLDL: Very low density lipoprotein. Data are expressed as mean \pm S.E.M. $(n=6)$. \#\#: $p<0.01$ as compared to NC; *: $p<0.05,{ }^{* *}: p<0.01$ as compared to DC. Data analysed by one way Analysis of Variance (ANOVA) followed by Dunnet's multiple test for comparison.

\section{Biochemical Parameters}

As shown in Table 1\&2, haemoglobin was significantly increased in EAHA treated diabetic rats as compared with the diabetic control group. Glycosylated haemoglobin was significantly $(\mathrm{p}<0.01)$ decreased in EAHA-treated diabetic rats a compared with the diabetic control group. Serum total protein and albumin were also significantly (p50.01) normalized by EAHA treatment. Diabetes control group showed a decrease in liver and skeletal muscle glycogen level. A significant $(\mathrm{p}<0.01)$ increase was noted in the glycogen content of liver and skeletal muscle as compared to diabetic control at the dose of $100 \mathrm{mg} / \mathrm{kg}$ and $200 \mathrm{mg} / \mathrm{kg}$. However there was no significant ( $\mathrm{p}>0.05$ ) increase in plasma insulin level of EAHA treated rats as compared to diabetic control rats.

Table 1: Effect of EAHA on biochemical parameters in STZ-nicotinamide induced diabetes in rats.

\begin{tabular}{|c|c|c|c|c|c|c|}
\hline Parameters & NC & DC & $\begin{array}{c}\text { DC+EAHA } \\
(100 \mathrm{mg} / \mathrm{kg})\end{array}$ & $\begin{array}{c}\text { DC+EAHA } \\
(200 \mathrm{mg} / \mathrm{kg})\end{array}$ & $\begin{array}{c}\text { DC+EAHA } \\
(400 \mathrm{mg} / \mathrm{kg})\end{array}$ & $\begin{array}{c}\mathrm{DC}+\mathrm{SG} \\
(3 \mathrm{mg} / \mathrm{kg})\end{array}$ \\
\hline Hemoglobin $\left(\mathrm{g} \mathrm{dl}^{-1}\right)$ & $13.60 \pm 0.44$ & $8.44 \pm 0.77^{\# \#}$ & $9.93 \pm 0.37^{* *}$ & $11.79 \pm 0.38^{* *}$ & $12.31 \pm 0.90^{* *}$ & $12.45 \pm 0.67^{* *}$ \\
\hline Glycosylated $\mathrm{Hb}(\mathrm{Hb} \%)$ & $5.55 \pm 0.347$ & $8.22 \pm 0.362^{\# \#}$ & $6.11 \pm 0.145$ & $5.76 \pm 0.18^{* *}$ & $5.90 \pm 0.39 * *$ & $4.91 \pm 0.26^{* *}$ \\
\hline Liver glycogen (mg/100) & $46.73 \pm 1.20$ & $9.09 \pm 1.42^{\# \#}$ & $28.28 \pm 1.54^{* *}$ & $33.66 \pm 0.96$ & $44.89 \pm 1.55$ & $38.75 \pm 1.36$ \\
\hline $\begin{array}{l}\text { Skeletal muscle glycogen } \\
(\mathrm{mg} / 100)\end{array}$ & $26.013 \pm 1.70$ & $11.13 \pm 0.86^{\# \#}$ & $14.22 \pm 2.19$ & $23.44 \pm 1.48^{* *}$ & $26.16 \pm 0.98^{* *}$ & $23.53 \pm 1.41$ \\
\hline Serum total protein $(\mathrm{g} / \mathrm{dl})$ & $8.07 \pm 0.62$ & $2.99 \pm 0.34^{\# \#}$ & $5.49 \pm 0.42$ & $7.35 \pm 0.21^{* *}$ & $8.25 \pm 0.66^{* *}$ & $8.25 \pm 0.66$ \\
\hline Serum albumin (g/dl) & $9.03 \pm 0.32$ & $3.49 \pm 0.36^{\# \#}$ & $4.71 \pm 0.21$ & $5.25 \pm 0.12^{* *}$ & $5.99 \pm 0.18^{* *}$ & $4.23 \pm 0.21$ \\
\hline Plasma insulin $(\mu \mathrm{IU} / \mathrm{ml})$ & $14.54 \pm 1.09$ & $2.66 \pm 0.23^{\# \#}$ & $2.57 \pm 0.19$ & $3.08 \pm 0.19$ & $2.95 \pm 0.29$ & $7.49 \pm 0.51^{* *}$ \\
\hline
\end{tabular}

NC: Normal control; DC: Diabetic control; EAHA: Ethyl acetate fraction of Holarrhena antidysenterica Linn. leaves; SG: Sitagliptin; S. muscle: Skeletal muscle; Data are expressed as mean \pm S.E.M. $(n=6)$; \#\#: $p<0.01$ as compared to NC; **: $p<0.01$ as compared to DC. Data analysed by one way Analysis of Variance (ANOVA) followed by Dunnet's multiple test for comparison. 
Table 2: Effect of EAHA on antioxidant parameters in liver and kidney.

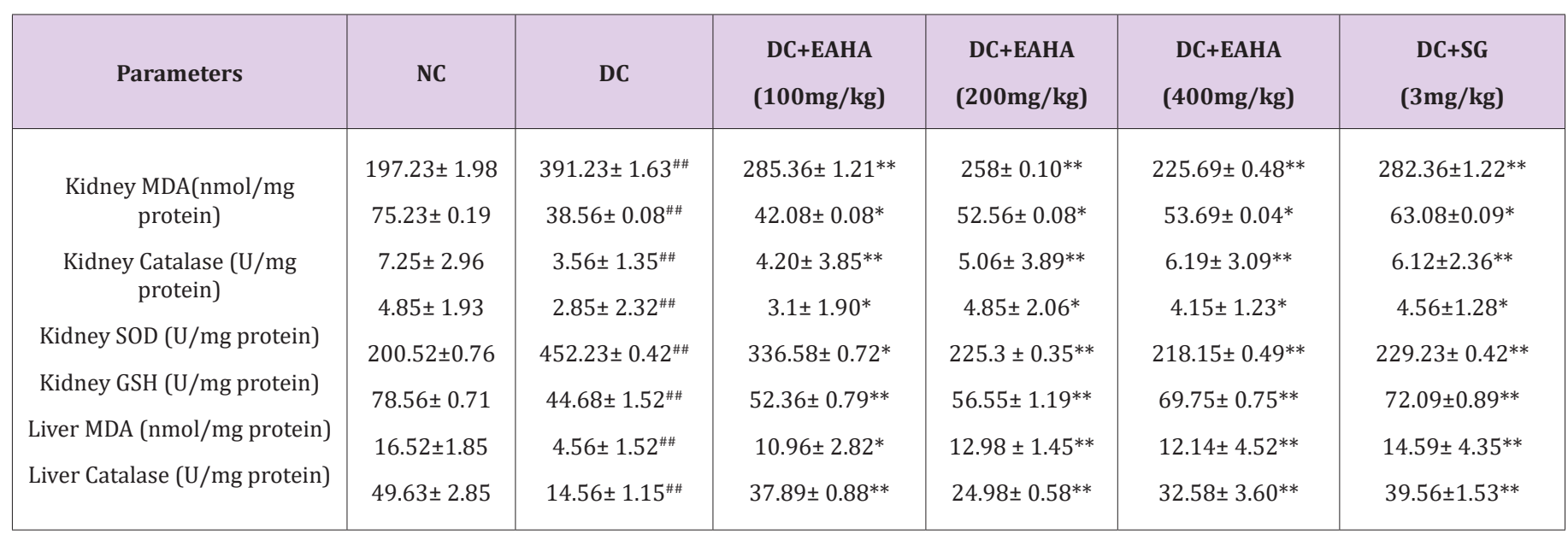

NC: Normal control; DC: Diabetic control; EAHA: Ethyl acetate fraction of Holarrhena antidysenterica Linn. Leaves; SG: Sitagliptin. Data are expressed as Mean \pm S.E.M. $(n=6)$. \#\#p<0.01 as compared with $N C ;{ }^{*} p<0.05,{ }^{* *} p<0.01$ as compared with DC. Data analysed by a one-way analysis of variance (ANOVA) followed by Dunnet's multiple test for comparison.

\section{Body Weight, Foot Intake, \& Water Intake}

As shown in Table 3, treatment with EAHA for $28 \mathrm{~d}$ significantly $(p<0.05)$ increased the body weight compared with diabetic control groups. Food intake was significantly high in diabetic control rats as compared with the normal control. At the end of $28 \mathrm{~d}$ of treatment food intake of treated groups significantly $(p<0.01)$ decreased as compared with the diabetic control. A significant decrease ( $p$ $<0.01$ ) in the water intake was observed in EAHA-treated groups as compared with the diabetic control at the end of the study period.

Table 3: Effect of EAHA on body weight, food intake and water intake in STZ diabetic rats.

\begin{tabular}{|c|c|c|c|c|c|c|}
\hline \multirow{2}{*}{$\begin{array}{c}\text { Experimental } \\
\text { groups }\end{array}$} & \multicolumn{2}{|c|}{ Body weight (g) } & \multicolumn{2}{|c|}{ Food intake (g/24h) } & \multicolumn{2}{|c|}{ Water intake (ml/24h) } \\
\hline & Initial & Final & Initial & Final & Initial & Final \\
\hline \multicolumn{7}{|l|}{ Normal control } \\
\hline Diabetic control & $214.6 \pm 17$ & $227.1 \pm 17.66$ & $15 \pm 0.975$ & $17.20 \pm 1.14$ & $22 \pm 3.20$ & $19.5 \pm 1.93$ \\
\hline \multirow{2}{*}{$\begin{array}{c}\text { DC+EAHA (100mg/ } \\
\mathrm{kg})\end{array}$} & $181 \pm 15.38^{\# \#}$ & $121.5 \pm 8.05^{\# \#}$ & $15.84 \pm 1.12^{\# \#}$ & $28.30 \pm 2.27^{\# \#}$ & $50.3 \pm 3.54^{\# \#}$ & $50.3 \pm 3.70^{\# \#}$ \\
\hline & $176.33 \pm 16.22$ & $204 \pm 24.21$ & $23.66 \pm 0.99$ & $16.33 \pm 0.88^{* *}$ & $48.5 \pm 3.60$ & $21.83 \pm 1.797^{* *}$ \\
\hline $\begin{array}{c}\text { DC+EAHA (200mg/ } \\
\mathrm{kg})\end{array}$ & $168.83 \pm 9.82$ & $131.3 \pm 7.27^{* *}$ & $14.56 \pm 0.70$ & $15.90 \pm 0.60^{* *}$ & $38 \pm 3.32$ & $52 \pm 1.24^{* *}$ \\
\hline \multirow{2}{*}{$\begin{array}{c}\text { DC+EAHA (400mg/ } \\
\mathrm{kg})\end{array}$} & $193.67 \pm 4.33$ & $194.17 \pm 4.83^{* *}$ & $27 \pm 3.055$ & $17.66 \pm 1.11^{* *}$ & $36.5 \pm 2.37$ & $18.16 \pm 0.79^{* *}$ \\
\hline & $177.4 \pm 7.69$ & $124.20 \pm 10.78^{* *}$ & $16.89 \pm 1.77$ & $23.20 \pm 2.27^{* *}$ & $38.6 \pm 3.38$ & $47.6 \pm 2.88^{* *}$ \\
\hline $\mathrm{DC}+\mathrm{SG}(3 \mathrm{mg} / \mathrm{kg})$ & & & & & & \\
\hline
\end{tabular}

NC: Normal control; DC: Diabetic control; EAHA: Ethyl acetate fraction of Holarrhena antidysenterica Linn. Leaves; SG: Sitagliptin Data are expressed as Mean \pm S.E.M. $(n=6)$. \#\#p $<0.01$ as compared with $N C ;{ }^{* *} p<0.01$ as compared to DC. Data analysed by a oneway analysis of variance (ANOVA) followed by Dunnet's multiple test for comparison.

\section{Histopathology Study}

As shown in Figure 3, STZ treated pancreatic sections showed clear decrease in the area occupied by the beta cells probably due to reduction in the number of beta cells. Sections of pancreas treated with HEAS had clearly shown the protective effect on histology of pancreas.

\section{Discussion}

The prevalence of diabetes mellitus is increasing with ageing of the population and lifestyle changes associated with rapid urbanization and westernization [31,32]. Diabetic complications including diabetic neuropathy, nephropathy, retinopathy and peripheral vascular diseases result in increasing disability, reduced life expectancy and enormous health costs virtually in every strata of society [33]. Metabolic defects that characterize type-II diabetes mellitus are $\beta$-cell defects leading to disturbances in insulin secretion and insulin resistance. As a result there is impaired utilization of glucose and inability of insulin to stimulate glucose uptake and disposal in tissues [34-36]. Several management strategies have been proposed for the early stages of hyperglycemia, with the aim of preventing the development of diabetes and associated complications. The current treatments of diabetes mellitus include 
diet, exercise, various oral antidiabetic dugs and insulin therapy [37]. However no single drug can target diabetes and its associated complications hence for effective control of diabetes, combination therapy is being considered. This necessitates the identification of novel drugs which might function in a mechanistically distinct fashion to the existing drug targets.

Indigenous medicinal system has always been a source of drugs and many of the currently available drugs have been derived directly or indirectly from the plants available in the system. Holarrhena antidysenterica Linn (Family Apocynaceae) commonly known as Kutja is a typical Indian medicinal plant employed for long time in folklore therapy. In Indian traditional medicine, leaves of the plant are used as an anti-diabetic remedy, however there is no scientific basis for the folklore use. We therefore undertook the present study to provide a scientific basis for the traditional use of Holarrhena antidysenterica leaves for the management of diabetes. A recently introduced animal model of type-II diabetes has been introduced by combined use of STZ and nicotinamide in adult rats [21]. STZ is documented to cause pancreatic $\beta$-cell damage, whereas nicotinamide being an antioxidant, exerts protective effect on the cytotoxic action of STZ by scavenging free radicals. This results in minor damage to pancreatic $\beta$-cell mass producing type-II diabetes $[38,39]$. In the present study, significant increase in glucose level in diabetic rats demonstrated the induction of diabetes by STZ- NA administration. The observed increase in the fasting blood glucose may be due to the damage to the pancreatic $\beta$-cells thereby affecting the insulin secretion or due to insensitivity of peripheral tissues for the action of insulin. Moreover increased glucose production in several animal models of type-II diabetes is a result of chronic insulin deficiency and insulin insensitivity [40]. To find out the probable mechanism of antihyperglycemic effect, we measured plasma insulin and carried out histopathology of pancreas. We found that the plasma insulin levels were not improved in EAHA treated diabetic rats as compared to diabetic control and histopathology study of pancreas showed no improvement in histology of pancreas of EAHA treated groups. This has indicated that the EAHA might not act by increasing the insulin secretion by pancreatic $\beta$-cells. There may be involvement of extrapancreatic mechanism including regulation of post prandial glucose level, improvement in sensitivity of target tissues or improvement in peripheral glucose utilization. This aspect of mechanism is further strengthened by an oral glucose tolerance test is an indication of early abnormalities in glucose regulation besides fasting plasma glucose or glycosylated hemoglobin. Impaired glucose tolerance in diabetic control group indicates reduced uptake of glucose from blood into skeletal muscle and adipose tissue following a meal [41-44]

EAHA increases the glucose tolerance of STZ- nicotinamide induced diabetic rats compared to diabetic control rats. Improvement in control of post-prandial glucose level in OGTT by EAHA indicated that EAHA may mediate regulation of glucose uptake from the intestinal lumen, through the inhibition of carbohydrate digestion or absorption. To strengthen the effect of EAHA on post prandial glucose level, we studied effect of EAHA on in vitro $\alpha$-amylase and $\alpha$-glucosidase enzymes. In the present work inhibition of $\alpha$-glucosidase enzyme by EAHA indicates its potential to delay or inhibit the carbohydrate breakdown and subsequent glucose absorption from the intestine. Inhibitory effect of EAHA on $\alpha$ - amylase enzyme indicates its probable potential to delay starch hydrolysis. The inhibitory effect on $\alpha$-glucosidase and $\alpha$-amylase enzyme proves that the antihyperglycemic activity of EAHA is partly due to its ability to regulate postprandial blood glucose level. To substantiate the role of EAHA in improving peripheral glucose utilization we evaluated its effect on liver and skeletal muscle glycogen. In diabetes mellitus, insulin deficiency causes reduced liver glycogen store as a result of inactivation of the glycogen synthetase systems $[45,46]$. The rise in liver and glycogen content by EAHA might be a result of increase in sensitivity of target tissues for insulin or may be due to insulin like action of EAHA that mediated increase in conversion of glucose to glycogen in the target tissues. Persistent hyperglycemia results in glycation of hemoglobin that leads to the formation of glycosylated haemoglobin which in turn is one of the important parameter that helps in prognosis of diabetes associated complications $[47,48]$. Decrease in the levels of glycosylated hemoglobin in diabetic rats treated with EAHA in our present study indicates the role of EAHA in maintaining the controlled blood glucose level and preventing oxidative damage caused by glycation reaction in diabetic conditions.

The risk of coronary heart disease is increased in diabetes mellitus due to profound alterations in plasma lipids and lipoprotein profile. It is well known that the level of glycemic control is the major determinant of serum level of very low density lipoproteins (VLDL) and triglycerides (TG). In the present study, streptozotocinnicotinamide induced diabetic rats exhibited clear cut abnormalities in lipid metabolism as shown by significant elevation of plasma total cholesterol, triglycerides, low density lipoprotein cholesterol, very low density lipoprotein cholesterol and atherogenic index with simultaneous decrease in HDL cholesterol levels. The rise in the plasma lipids especially triglycerides in diabetic rats indicates increased mobilization of free fatty acids from peripheral depots through mechanism called glucose-fatty acid cycle [40]. The effect of EAHA on diabetic hypercholesterolemia and hypertriglyceridemia could be through its control on hyperglycemia. This is in agreement with the fact that the level of glycemic control is the major determinant of total and very low density lipoprotein triglyceride concentrations [49]. Reduction of triglycerides by EAHA would also facilitate the glucose oxidation, its utilization and subsequently the reduction of hyperglycemia. EAHA by their ability to decrease the levels of LDL-cholesterol and triglycerides in diabetic rats may play a role in alleviating complications of diabetes such as atherosclerosis and coronary heart disease. Thus glucose lowering action of EAHA could be due to its consequence of an improved lipid metabolism apart from the direct effect on glucose 
homeostasis. Further the protective effect of EAHA on lipid profile may be due to the presence of flavonoids, which are reported to have upregulatory effect on LDL receptors [50,51]. Disturbances in carbohydrate, lipid and protein metabolism together with oxidative stress are likely to affect renal functions in diabetic condition which is characterized by a marked decrease in plasma proteins. It results due to an increased glycogen breakdown and gluconeogenesis with protein degradation. To prove the effect of EAHA in regulating gluconeogenesis we evaluated the serum total protein and serum albumin level in STZ-nicotinamide diabetic rats. In the present study, the increase in serum total protein and albumin in STZnicotinamide diabetic rats by EAHA treatment may be due to the insulin like action of EAHA thereby controlling gluconeogenesis.

Increased levels of aspartate transaminase (AST), alanine transaminase (ALT) and alkaline phosphatase (ALP) are reported as predictors of diabetes and under insulin deficiency in diabetic condition these enzymes increase gluconeogenesis and ketogenesis [52]. Further, the elevation in the levels of these gluconeogenic enzymes could indicate impairment in insulin signaling rather than purely hepatocytes injury. Rise in ALT, AST and ALP levels in STZ-nicotinamide induced diabetic rats in the present study may involve increased liberation of these enzymes from tissues, owing to oxidative stress or the formation of advanced glycosylation end products. Significant reduction in the activities of these enzymes in EAHA treated diabetic rats may be because of potentiating effect of exhisting circulating insulin or decrease cellular damage [53]. The protective effect of EAHA on liver functioning in diabetic rats is partly due to its antioxidant activity. The destruction of $\beta$-cells during diabetes ultimately causes physic-metabolic abnormalities such as a decrease in body weight gain. A notable decrease in the body weight observed in the diabetic group in the present study might be the result of protein wasting due to the unavailability of carbohydrates for energy metabolism and the loss or degradation of structural proteins as reported earlier $[54,55]$. The improvement in body weight in diabetic rats supplemented with EAHA highlight the blood glucose homeostasis which in turn promotes the body weight gain. Hyperglycemia is a well-known cause for production of reactive oxygen species (ROS) which can lead to increased lipid peroxidation [56,57]. SOD is an important defense enzyme that catalysis the dismutation of superoxide radicals [58]. Catalase is the hemoprotein that catalysis the reduction of hydrogen peroxides and protects the tissues from highly reactive hydroxyl radicals. GSH plays a multifactorial role in antioxidant defense and serves as a co-substrate for peroxide detoxification of glutathione peroxidase $[59,60]$.

In the present study, improvement in renal SOD, CAT and GSH enzymes after treatment with EAHA indicates its beneficial effect against the pathological alteration caused by the presence of superoxide and hydroxyl radicals. The restoration of renal SOD, CAT and GSH contents in STZ-diabetic rats thus reflects that besides antihyperglycemic activity, EAHA also possess antioxidant potential which assisted in preventing diabetes induced oxidative stress and associated complications. The antioxidant potential of EAHA was further strengthened by studying the effect on lipid peroxidation. The MDA level determination provides a good measure of peroxidation which is one of the chief mechanisms of cell damage leading to necrosis and apoptosis [61]. Our present study showed that EAHA reduced the MDA level in liver and kidney of diabetic rats indicating its ability to scavenge reactive oxygen species, to inhibit lipid peroxidation and to protect the tissues against oxidative damage. Thus the therapeutic utility of EAHA may also be partly due to their ability to decrease the generation of reactive oxygen species, a process that results in oxidative stress and aggravates the diabetic state. EAHA by its ability to scavenge free radicals and to inhibit lipid peroxidation, prevented STZ-NA induced oxidative stress and protected beta cells from further damage resulting in decreased blood glucose levels. The antihyperglycemic activity of EAHA is thus associated with decrease in glucose toxicity resulting in protection from the toxic effects of reactive oxygen species. Thus in addition to the antidiabetic and antihyperlipidemic effects, EAHA also possess antioxidant potential that may be beneficial for correcting the hyperglycemia and preventing the diabetic complications due to lipid peroxidation and free radicals. In the present study STZ-nicotinamide induced diabetic rats exhibited typical symptoms like polyphagia, polydipsia and polyuria as reported by other researchers [62]. In the present work, EAHA showed dose dependent decrease in food and water intake in STZ diabetic rats which may be because of increased utilization of glucose by the body.

\section{Conclusion}

EAHA exhibits antihyperglycemic activity against STZ-NA induced diabetes in rats and is attributed to its major flavonoid quercetin. The ability of EAHA to reduce lipid profile especially triglycerides and low density lipoprotein cholesterol could represent a protective mechanism against the development of atherosclerosis and associated cardiovascular complications in diabetic conditions. The antihyperglycemic activity of EAHA may be due to insulin-like effect of EAHA or it could be due to the ability of EAHA to protect the intact functional beta cells from further deterioration so that they remain active and continue to produce insulin which further act on peripheral tissues for promoting glucose uptake and metabolism, or by inhibiting hepatic gluconeogenesis. In view of increasing incidence of diabetes mellitus in rural populations throughout the world, inability of current therapies to control all the metabolic defects of the disease, their pathological consequences and the great expense of modern therapy, study of antihyperglycemic potential of EAHA may prove an alternative strategy for diabetic therapy.

\section{References}

1. Akbarzadeh A, Noruzian D, Jamshidi SH, Farhangi A, Mehrabi MR (2007) Treatment of streptozotocin induced diabetes in male rats by immunoisolated transplantation of islet cells. Indian J Clin Biochem 22(1): 71-76. 
2. West IC (2000) Radicals and oxidative stress in diabetes. Diabetic Med 17(3): 171-80.

3. Menaka CT, Ravirajsinh NJ, Ansarullah T, Ranjitsinh VD, Ramachnadran AV (2010) Prevention of high fat diet induced insulin resistance in mice by Sida rhomboidea extract. J Health Sci 56: 92-98.

4. Gupta RK, Kesari AN, Murthy PS, Chandra R (2005) Hypoglycemic and antidiabetic effect of ethanolic extract of leaves of Annona squamosa L. in experimental animals. J Ethno pharmacol 99(1): 75-81.

5. Kumar S, Yadav A (2015) Comparative Study of Hypoglycemic Effect of Holarrhena antidysenterica seeds and Glibenclamide in Experimentally Induced Diabetes Mellitus in Albino Rats. Biomed Pharmacol J 8: 477 483.

6. Kumar N (2007) Steroidal Alkaloids from Holarrhena antidysenterica. Pharm Bull 55(6): 912-914.

7. Gurib FA (2006) Medicinal plants: traditions of yesterday and drugs tomorrow. Molecular Aspects of Medicine 27(1): 1-93.

8. Gupta RK, Kesari AN, Murthy PS, Chandra R, Tandon V, et al. (2005) Hypoglycemic and antidiabetic effect of ethanolic extract of leaves of Annona squamosa L. in experimental animals. J Ethno pharmacol 99(1): 75-81.

9. Okonta JM, Aguwa CN (2007) Evaluation of hypoglycemic activity of glycosides and alkaloids extracts of Picralima nitida Stapf (Apocynaceae) seed. Int J Pharmacol 3(6): 505-509.

10. Kokate CK, Purohit AP, Gokhale SB (2005) Text book of Pharmacognosy. In: Kokate CK, Purohit AP, Gokhale SB(Eds.), (38 ${ }^{\text {th }}$ edn.). CBS publication, Nirali Prakashan, 13-77.

11. Kumar A, Ali M (2000) A new steroidal alkaloid from the seeds of Holarrhena antidysenterica. Fitoterapia 71(2): 101-104.

12. Jalalpure SS, Bamne S, Patil MB (2006) Anti-diabetic activity of Holarrhena antidysenterica (Linn.) Wall, bark on alloxan induced diabetic rats. J Nat Remed 6(1): 26-30.

13. Hegde K, Jaisal KK (2014) Anti-diabetic potential of ethanolic extract of Holarrhena antidysenterica Linn leaves. Inter J Pharma Sci Res 5: 429435.

14. Patel AN, Bandawane DD, Mhetre NM (2015) Flavonoid rich fraction of Punica granatum improves early diabetic nephropathy by ameliorating proteinuria and disturbed glucose homeostasis in experimental animals. Pharm Biol 53(1): 61-71

15. Shwetha C, Latha KP, Pushpa B, Shruthi A, Vaidya VP (2011) Phytochemical screening and evaluation of in-vitro antioxidant activity, total phenolics and total flavonoids of Holarrhena antidysentrica leaf extracts. Inter J Res Pharm Chem 1(3): 546-550.

16. (2000) WHO Quality Control Methods for Medicinal Plant Materials. World Health Organization, Geneva, p. 50.

17. Zhishen J, Mengcheng T, Jianming W (1999) Research on antioxidant activity of flavonoids from natural materials. Food Chem 64: 555-559.

18. Husain MS, Fared S, Ali M, Raman MA (2012) Validation of the method for the simultaneous estimation of biomarkers gallic acid and quercetin in Abutilon indicum by HPTLC. Asian Pac J Trop Med S76-83.

19. Ranilla LG, Kwon YI, Apostolidis E, Shetty K (2010) Phenolic compounds, antioxidant activity and in vivo inhibitory potential against key enzymes relevant for hyperglycemia and hypertension of commonly used medicinal plants, herbs and spices in Latin America. Biores Tech 101(12): 4676-4689.

20. Jaydeokar AV, Bandawane DD, Bibwe KH, Patil TV (2014) Hepatoprotective potential of Cassia auriculata roots on ethanol and anti-tubercular drug induced hepatotoxicity in experimental animals. Pharm Biol 52(3): 344-355.

21. Masiello PC, Broca R, Gross M, Roye M, Manteghetti D, et al. (1998) Experimental NIDDM: development of a new model in adult rats administered streptozotocin and nicotinamide. Diab 47(2): 224-229.
22. Wang Z, Yang Y, Xiang X, Zhu J, He M (2010) Estimation of the normal range of blood glucose in rats. Inst Nutr Food Saf 39(2): 133-137.

23. Bandawane DD, Bibave KH, Jaydeokar US, Patil US, Hivrale MG (2013) Antihyperglycemic and antihyperlipidemic effects of methanolic extract of Holarrhena antidysentrica bark in alloxan induced diabetes mellitus in rats. Pharmacolog 4(2): 95-106.

24. Friedewald WT, Levy RI, Fredrickson DS (1972) Estimation of the concentration of low-density lipoprotein cholesterol in plasma, without use of the preparative ultracentrifuge. Clin Chem 18(6): 499-502.

25. Kaur G, Zoobi J, Mohammad A, Sarwar Alam M (2006) Punica granatum (pomegranate) flower extract possesses potent antioxidant activity and abrogates Fe-NTA induced hepatotoxicity in mice. Food Chem Toxicol 44(7): 984-993.

26. Marklund SL (1985) Pyrogallol autooxidation. In: Greenwald RA, ed. Handbook of Methods for Oxygen Radical Research. Boca Raton: CRC Press, pp. 243-244

27. Sahreen S, Khan MR, Khan RA (2011) Hepatoprotective effects of methanol extract of Carissa opaca leaves on CCl4 induced damage in rat. Compl Alternat Med 11: 1-10.

28. Kumar RP, Sujatha, D, Saleem TSM, et al. (2010) Potential antidiabetic and antioxidant activities of Morus indica and Asystasia gangetica in alloxan-induced diabetes mellitus. J Exp Pharmacol 2: 29-36.

29. Carroll NVR, Longley W, Rae JH (1956) The determination of glycogen in liver and muscle by use of Anthrone reagent. J Biol Chem 220(2): 583598.

30. Luna L (1960) Manual of Histological Staining Methods of the Armed Forces Institute of Pathology. In: Luna L(Eds.), ( $3^{\text {rd }}$ edn.), McGraw-Hill Publications, New York, USA, pp: 125.

31. Kamalakkanan N, Rajadurai M, Prince PSM (2003) Effect of Aegle marmelose fruits on normal and streptozotocin - diabetic wistar rats. J Med Food 6(2): 93-98.

32. Sobngwi E, Mauvais Jarvis E, Vexiau P, Mbanya JC, Gautier JF (2001) Diabetes in Africans. Part 1: Epidemiology and Clinical Specificities. Diab Metabol 27(6): 628-634.

33. Allgot B, Gan D, King H, Lefebvre P, Mbanya JC, et al. (2003) Diabetes Atlas. In: Allgot B, Gan D, King H, Lefebvre P, Mbanya JC, et al. (Eds.), (2 ${ }^{\text {nd }}$ edn.). Executive Summary Brussels: International Diabetes Federation, p. 58.

34. Arulmozhi DK, Sridhar N, Bodhankar SL, Veeranjaneyulu A, Arora SK (2004) In vitro pharmacological investigations of Sapindus trifoliatus in various migraine targets. J Ethnopharmacol 95(2-3): 239-245.

35. Murugan P, Pari L (2006) Effect of tetrahydrocurcumin on plasma antioxidants in streptozotocin-nicotinamide experimental diabetes. J Basic Clin Physiol Pharmacol 17(4): 231-244.

36. Shulman GI (2000) Cellular mechanisms of insulin resistance. J Clin Invest 106(2): 171-176.

37. Pankaj NK, Alam M, Roy BK (2005) Antidiabetic activity of seed powder of Holarrhena antidysenterica in rabbits. J Res 17: 95-103.

38. Punitha IS, Rajendran K, Shirwalkar A (2005) Alcoholic stem extract of Coscinium fenestratum regulates carbohydrates metabolism and improves antioxidant statues in streptozotocin-nicotinamide induced diabetic rats. Evidence Based Complem Alternat Med 2(3): 375-381.

39. Szkudelski T (2012) Streptozotocin-nicotinamide induced diabetes in the rat: Characteristics of the experimental model. Exp Biol Med 237(5): 481-490.

40. Patel AN, Bandawane DD, Mhetre NK (2014) Pomegranate (Punica granatum Linn) leaves attenuated disturbed glucose homeostasis and hyperglycemia mediated hyperlipidemic and oxidative stress in streptozotocin induced diabetic rats. Eur J Integrat Med 6(3): 307-321.

41. Singleton JR, Smith AG, Russell JW, Feldman EL (2003) Microvascular complications of impaired glucose tolerance. Diab 52(12): 2867-2873. 
42. Robertson RP, Harmon J, Tran PO, Tanka Y (2003) Takahashi glucose toxicity in beta- cells type-2 diabetes, good radicals gone bad and the glutathione connection. Diab 52(3): 581-587.

43. Shim YJ, Doo HK, Ahn SY, Kim YS, Seong JK, et al. (2003) Inhibitory effect of aqueous extract from the gall of Rhus Chinensis on alpha-glucosidase activity and postprandial blood glucose. J Ethnopharmacol 85(2-3): 283 287.

44. Lee SH, Park MH, Heo SJ, Kang SM, Ko SC, et al. (2010) Dieckol isolated from Ecklonia cava inhibits $\alpha$ - glucosidase and $\alpha$ - amylase in vitro and alleviates postprandial hyperglycemia in streptozotocin-induced diabetic mice. Food Chem Toxicol 48(10): 2633-2637.

45. Das S, Barman S (2012) Antidiabetic and antihyperlipidemic effect of Punica granatum in alloxan induced non-insulin dependent diabetes mellitus in albino rats. Ind J Pharmacol 44(2): 219-224.

46. Shirwaikar A, Rajendran K, Dinesh Kumar C, Bodia R (2004) Antidiabetic activities of aqueous leaf extract of Annona squamosa in streptozotocinnicotinamide type 2 diabetic rats. J of Ethnopharmacol 91(1): 171-176.

47. Yabe Nishimura C (1998) Aldose reductase in glucose toxicity: a potential target for the prevention of diabetic complications. Pharmacol Rev 50(1): 21-33.

48. Howlett J, Ashwell M (2008) Glycemic response and health: summary of a workshop. Am J Clin Nutr 87(1): 212S-216S.

49. Laakso M (1995) Epidemiology of diabetic dyslipidemia. Diabet Rev 3(3): 408-422.

50. Rashid S, Takehiko Watanabe MD, Taro Sakaue MD, Gary F. Lewis MD (2003) Mechanisms of HDL lowering in insulin resistant, hypertriglyceridemic states: the combined effect of HDL triglyceride enrichment and elevated hepatic lipase activity. Clin Biochem 36(6): 421-429.

51. Leontowicz H, Gorinsteins Loje KA (2002) Comparative content of some bioreactive compounds in apples, peaches and pears. J. Nutr Biochem 13(10): 603-610

52. Lanjhiyana S, Garabadu D, Ahirwar D (2011) Pharmacognostic standardization and hypoglycemic evaluations of novel polyherbal formulations. Der Pharmacia Lett 3(1): 319-333.

\section{ISSN: 2574-1241}

DOI: 10.26717/BJSTR.2019.16.002821

Deepti Banadawane. Biomed J Sci \& Tech Res

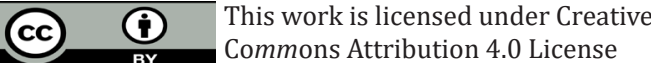

Submission Link: https://biomedres.us/submit-manuscript.php
53. Kumar S, Kumar V, Prakash 0 (2010) Antidiabetic, hypolipidemic and histopathological analysis of Dillenia indica (L.) leaves on alloxan induced diabetic rats. Asia Pac J Trop Med 4(5):347- 352

54. Mhetre NK, Bandawane DD, Patel AN (2013) Renoprotective effect of hydroalcholic extract of aerial parts of Cassia auriculata Linn. (Caesalpiniaceae) in streptozotocin induced early diabetic nephropathy in rats. Inter J Pharm Pharmaceutic Sci 5(4): 270-279.

55. Bandawane DD, Juvekar AR, Juvekar MR (2011) Antidiabetic and antihyperlipidemic effect of Alstonia scholaris Linn bark in streptozotocin induced diabetic rats. Ind J Pharm Edu Res 45(2): 114-120.

56. Bansal P, Paul P, Mudgal J, Nayak PG, Pannakal ST, et al. (2012) Antidiabetic, antihyperlipidemic and antioxidant effects of the flavonoid rich fraction of Pilea microphylla (L.) in high fat diet/ streptozotocininduced diabetes in mice. Expt Toxicol Pathol 64(6): 651-658.

57. Rekha N, Balaji R, Deecaraman M (2010) Antihyperglycemic and antihyperlipidemic effects of extracts of the pulp of Syzygium cumini and bark of Cinnamon zeylanicum in streptozotocin induced diabetic rats. J Appl Biosci 28: 1718-1730.

58. Liu Y, Sun J, Rao SS, Su Y, Yang Y (2013) Antihyperglycemic, antihyperlipidemic and antioxidant activities of polysaccharides from Catathelasma ventricosum in streptozotocin induced diabetic mice. Food Chem Toxicol 57: 39-45.

59. Ballatori N, Krance SM, Notenboom S, Shi S, Tieu K, et al. (2009) Glutathione dysregulation and the etiology and progression of human diseases. Biol Chem 390(3):191-214.

60. Singh AK, Singh J (2010) Evaluation of anti-diabetic potential of leaves and stem of Flacourtia jangomas in streptozotocin-induced diabetic rats. Ind J Pharmacol 42(5): 301-302.

61. Celik I, Temur A, Isik I (2009) Hepatoprotective role and antioxidant capacity of pomegranate (Punica granatum) flowers infusion against trichloroacetic acid-exposed in rats. Food Chem Toxicol 47(1): 145-149.

62. Okon UA, Owo DU, Udokang NE, Udobang JA, Ekpenyong CE (2012) Oral administration of aqueous leaf extract of Ocimum gratissimum ameliorates polyphagia, polydipsia and weight loss in streptozotocin induced diabetic rats. Amer J Med Sci 2(3): 45-49. 